\title{
Contar a vida, pensar a história - Experiências na utilização das fontes orais no ensino da História
}

Cleusa Maria Gomes Graebin ${ }^{1}$

Rejane Silva Penna ${ }^{2}$

\section{RESUMO}

0 artigo tem como objetivos refletir sobre os depoimentos orais como fontes para o estudo e o ensino da história e mostrar experiências de trabalho com fontes orais no ensino fundamental e no superior. Metodologicamente, abordamos a incorporação, ao ofício do historiador, das fontes orais como documentos e, consequentemente, o que podemos esperar deste tipo de fonte. Discutimos sobre a incorporação das fontes orais ao ensino de história em todos os graus de ensino e apresentamos exemplos de experiências de aplicação das fontes orais em sala de aula.

Palavias-chave: história, memória, fontes orais, ensino

\section{Introduç̃}

Este trabalho reflete sobre os depoimentos orais como novas fontes para 0 estudo e o ensino da história, bem como descreve experiências de trabalho com fontes orais em um curso superior de Licenciatura em História, bem como em outro de ensino fundamental. 0 artigo estrutura-se da seguinte maneira: primeiro abordamos a emergência das fontes orais como importante instrumento de compreensão da sociedade, integrando, gradativamente as pesquisas das ciências humanas, até a sua inserção em diversos centros de preservação da memória. Em segundo lugar, debatemos sobre o que se pode esperar das fontes orais, encaminhando argumentos para a possibilidade de utilização de acervos já constituídos por novos pesquisadores. A seguir, analisamos a incorporação dos depoimentos orais como

1 Dra. em História \Professora do Curso de História do Centro Universitário La Salle, Canoas, RS.

2 Dra. em História $\backslash$ Professora do Curso de História do Centro Universitário La Salle, Canoas, RS. 
recurso para o ensino da História, contribuindo com exemplos de sua aplicação em sala de aula, explicando a metodologia e refletindo sobre os resultados dos trabalhos realizados pelos alunos.

\section{Novas fontes para o estudo da História em tempos de crise identitåria}

Nossa contemporaneidade é marcada por discussões de temas como a identidade, sua perda, reafirmação ou transformação. Busca-se compreender a demanda de múltiplos segmentos para situar a si e aos outros em um mundo que, aparentemente, perdeu o pouco de solidez que tinha e a velocidade das transformações ameaça apagar diversos registros da trajetória humana. Multiplicam-se indagações quanto a se estaríamos condenados a viver, equilibrando-nos em um frágil presente que não forneceria a base necessária da experiência vivida a auxiliar-nos na constante indagação de quem somos.

Perdemos nossas certezas, e até ferramentas teóricas que forneciam uma certa segurança sobre o devir sofrem dificuldades em explicar um mundo que teima em surpreender, tornando obsoletas ou insuficientes teorias e campos do conhecimento que buscaram enquadrá-lo em teleologias dos mais diversos matizes. As Ciências Humanas foram atingidas pela modernidade (no sentido de contemporaneidade) que tanto descreveram e analisaram, e a violência do choque enfraqueceu à muitas disciplinas como instâncias privilegiadas de explicação do mundo.

Entretanto, talvez por ter sempre mantido a diversidade e a discussão teórica (independente do fato de existirem algumas hegemonias) e aceitado que vivia uma crise de paradigmas, o estudo da História sobreviveu, e mais, fortaleceu-se. Os cursos têm intensa procura e crescem as publicações, desde 0 retorno da biografia, renovada e problematizada, até os polêmicos estudos sobre etnias, gênero e cotidianos.

E é assim, neste universo permeado pela perda de referências do passado que se aprofundam os laços entre Memória e História, mesmo que exista uma oposição entre 0 universo da memória, situada como experiência vivida, imagem e afeto e 0 da História, situada como crítica, problema, conceitos (SILVA, 2003, p. 437).

Ocorre que as mudanças conjunturais impuseram aos atores históricos o dever da memória e os novos questionamentos epistemológicos, valorizadores 
da parte subjetiva no trabalho de objetivação histórica, provocaram deslocamentos, levando os historiadores a buscar uma reaproximação entre Memória e História (SILVA, 2003, p. 437).

Nesse sentido, pode-se recuperar o trajeto de uma fonte histórica que, mais do que qualquer outra, relaciona-se com a memória, mantendo até hoje profícua, porém difícil relação com a História: a fonte oral, como denomina-se o depoimento de um ser humano a outro, filmado ou gravado.

Os que consideraram as fontes orais como relevantes criaram métodos de análise e de entrevista que se fundamentaram num entendimento mais complexo da memória e da identidade e sugeriram meios novos e estimulantes para tirar o maior proveito das memórias para fins de pesquisa histórica. Procuraram explorar as relações entre reminiscências individuais e coletivas, entre memória e identidade, ou entre entrevistador e entrevistado, fazendo com que 0 trabalho com fontes orais passasse a ocupar lugar destacado no conjunto mais amplo de estudos inovadores sobre História social e cultural.

0 Brasil não ficou à margem dessas discussões. Por aqui, o uso de entrevistas orais como fonte de informação para pesquisas já era procedimento, até certo ponto corrente, entre cientistas sociais, mas não havia a preocupação de, a partir da relação entre depoentes e pesquisador, mediada por um gravador, produzir documentos. 0 momento foi analisado por Marieta de Moraes Ferreira, na introdução de uma coletânea sobre pesquisas que integraram as fontes orais, no que o meio historiográfico denominou de História Oral:

A novidade dos programas de História Oral do CPDOC e do Departamento de História da Universidade Federal de Santa Catarina foi exatamente propor a constituição de acervos de depoimentos orais de História de vida, de representantes da elite política brasileira. Ainda que esse novo campo de trabalho despertasse, na época, pouco interesse e, em alguns casos, fortes resistências, a possibilidade de sua afirmação pode ser explicada a partir da abertura de novos centros de pesquisa e programas de pósgraduação nas universidades brasileiras (FERREIRA, 1994, p. 9).

0 contexto político-social dos anos setenta contribuiu para que visões alternativas ou chamadas de esquerda abrissem espaço para a introdução de novas práticas de pesquisa, buscando lugar nas Universidades que ainda, majoritariamente, 
concentravam seus estudos no Brasil colonial e no século XIX, chegando, no máximo, a abordar o período republicano, até a Revolução de Trinta.

Adiante, os anos 1980 representaram, no campo acadêmico, a consolidação de vários programas de pós-graduação em História e Ciências Sociais, com orientações mais amplas, enfocando a História social e cultural. Pesquisadores encontraram espaço para produzir trabalhos com História Oral, explorando temáticas como a classe trabalhadora brasileira, a História de bairros, as minorias e grupos discriminados, como negros e mulheres.

Aspásia Camargo analisou sobre a motivação dos pesquisadores a utilizarem as fontes orais:

partimos então da idéia de que havia filtros de várias naturezas para estudar o processo de montagem do Estado brasileiro nos anos 30: havia o filtro dos atores que montaram esse processo e o filtro dos que foram contrários a ele; aliás, este era o único filtro mais organizado. Com isso, às vezes, "jogávamos o bebê com a água do banho". Tínhamos, portanto, que construir uma mediação entre o que os atores diziam e o que nós poderíamos dizer sobre aquela realidade: se houve atores que construíram um determinado processo, isso devia ter uma certa lógica, e o importante para nós era capturar essa lógica, e não simplesmente criticar os atores (CAMARG0, 1999, p.152).

Hoje, um dos campos em que mais se publica é o da História Oral. Existem alguns trabalhos considerados já clássicos, mesmo não sendo escritos por historiadores, caso de Ecléa BOSI, em Memória e sociedade: lembranças de velhos (1994).

Por fim, a opção de utilizar as fontes orais é profundamente ligada a uma determinada condição teórica, a uma escolha de como narrar, analisar e expor determinado contexto, grupo social ou manifestação cultural.

\section{0 que podemos esperar das fontes orais}

Independentemente do fato de multiplicarem-se trabalhos que incorporam as fontes orais, conforme descrito anteriormente, ainda hoje, sua utilização em pesquisas e publicações de caráter histórico tem sido acompanhada de polêmicas e hesitações. 
Parte do problema deve-se ao fato de que a inclusão deste tipo de fonte na historiografia, inicialmente (e, por vezes, até hoje), revestiu-se de caráter empírico, não sendo reconhecido algo como um texto-fundador que norteasse e esboçasse um corpo de proposições unificadas (PENNA, 2003, p. 48).

A metodologia da História Oral insere-se nas teorias históricas que pressupõem a ampliação da noção de fonte histórica e que consideram existir múltiplas representações sobre o vivido. Cabe-nos interpretá-las. Para tanto é necessário discutir a complexidade das fontes orais.

Existem modos de proceder baseados em duas maneiras diferentes de tratar o documento: um que confere maior importância à precisão factual e à informação e outro, mais preocupado com o que revelam as interpretações sobre os fatos. No segundo caso, trata-se, basicamente, da narrativa do indivíduo, de suas experiências e é limitada pelo tempo possível de vida que se testemunhou.

0 uso de tal reminiscência tem sido, até agora, a maior contribuição de historiadores como Paul Thompson, utilizando os dados orais, para dar voz àqueles que não se expressaram no registro documental. Entre as fontes orais e as fontes escritas, mesmo que as segundas tenham também uma carga de subjetividade, esta é incomparavelmente menor do que nas fontes orais. Principalmente as fontes escritas, provenientes de documentos que não têm a função original de servirem de fontes históricas, como inventários, registros de atos públicos, orçamentos etc. Mas, ressaltamos, as fontes orais não podem ser simples substitutas e de segunda categoria das fontes escritas, mas consideradas de outra natureza, prestando-se a determinado tipo de análise histórica.

Esse ponto de vista pode ser complementado com os argumentos de CRUIKSHANK:

É um erro equiparar os depoimentos orais aos documentos escritos, diz ele. Assim que o fazemos, passamos inevitavelmente a conceber a tradição oral como "uma narrativa não distorcida, transmitida através de um conduto" e a avaliar o que ouvimos em termos positivistas. Isso leva ao mesmo erro cometido pelos primeiros folcloristas: à busca dos assim chamados relatos originais, autênticos ou acurados. Quando agimos desse modo, pode nos escapar por completo o que a tradição oral realmente faz e como é usada" (apud FERREIRA, 1996, p. 157). 
Para ele, nenhum historiador da alta política moderna, tendo base nos registros públicos, pode esperar ser lido com confiança, se as fontes orais (e, pode-se acrescentar, as fontes fotográficas e filmográficas) não tiverem sido empregadas, proporcionando detalhes que de outra forma seriam inacessiveis, estimulando o historiador a reanalisar de maneira nova.

Acrescente-se a inevitabilidade de lidar com este tipo de fonte, frente aos desafios da contemporaneidade, a fim de não se tornar um profissional que apenas é consultado quando se pensa em tombar algum antigo prédio ou para palestrar sobre efemérides.

Aceitar este desafio é tornar-se um historiador no sentido amplo, extraindo os materiais de fontes adequadas para estudar toda a variação de escalas e problemas na História contemporânea.

\section{Inserindo as fontes orais no ensino da História}

A seguir, expomos dois tipos de experiências na utilização de fontes orais no ensino de História. Primeiramente, no ensino superior, com alunos da disciplina de Prática de Ensino/História-Licenciatura e a seguir, um trabalho realizado por alunos da mesma disciplina no estágio de docência no ensino fundamental.

\subsection{História local e memórias de imigrantes: algumas experiências na formação de professores}

SAMUEL (1989) chama a atenção para duas concepções ainda presentes no ofício do historiador: a abordagem da história local, considerando a cidade, como entidade distinta, fenômeno único, conjunto cultural com periodização própria; e os documentos tomados pelo valor que, supostamente, encerrariam em si mesmos. Para fugir destas armadilhas, o autor indica a escolha de um ponto de partida limitado no tempo e no espaço, algum elemento da vida na cidade, o qual será usado como janela para o mundo.

Assim, ao eleger o local como circunscrição de análise, pode-se partir de experiências de grupos ou de indivíduos, da tessitura de relações plurais que envolvem solidariedades, normas, constrangimentos, dominação, adaptações, acomodações e resistências (REVEL, 1988, pp. 15-38). 
Quanto às fontes, SAMUEL (1989) recomenda prestar atenção na compreensão dos textos, os silêncios e as omissões da documentação escrita. Neste sentido, os testemunhos orais constituem-se em fontes privilegiadas para os estudos de história local. A sua incorporação permite que os pesquisadores acrescentem perspectivas diferentes em termos de vida cotidiana, de conflitos e experiências vividas.

A partir destes pressupostos, concluímos que seria importante trabalhar uma abordagem sob o recorte da história local na disciplina de Prática de Ensino, do curso de História - Licenciatura, na cidade de Canoas, situada na Região Metropolitana de Porto Alegre, Rio Grande do Sul.

Canoas teve sua origem, no século XVIII, durante a expansão e ocupação portuguesa no Sul do Brasil. Originariamente, integrava a sesmaria de Francisco Pinto Bandeira, conhecida como Fazenda do Gravataí. Seu processo de urbanização iniciou nas últimas décadas do séc. XIX, através de loteamentos do espaço da antiga Fazenda. 0 fator desencadeador foi a abertura de via férrea, ligando Porto Alegre a São Leopoldo e a instalação de uma estação, onde, atualmente, está o centro da cidade.

Durante o século XX, passou por um processo de industrialização e crescimento urbano e a partir da década de vinte, começou a receber contingentes de imigrantes das mais diferentes procedências, os quais instalaram-se na cidade, dando origem a alguns dos seus bairros.

Então, propusemos aos alunos que elaborassem projetos de pesquisa cujos objetivos deveriam estar centrados na análise dos processos de construção/ reconstrução das identidades sociais dos imigrantes, particularizando os sentimentos de pertencimento e vínculos afetivos, bem como as relações de poder tecidas entre indivíduos, grupos e instituições.Adotamos para o estudo, procedimentos que, segundo REVEL (1988), desvelam as formas pelas quais, indivíduos ou grupos, no interior de uma configuração dada, constituem e refazem identidades coletivas.

Nossa intenção com este trabalho foi a de demonstrar para os futuros professores que ensinar história não se limitava a transmitir conhecimentos já acumulados, mas, principalmente, possibilitar a produção e construção de novos conhecimentos. É preciso, permanentemente, que o professor tenha $-\mathrm{e}$ leve os alunos a cultivar - uma "atitude de questionamento e curiosidade, a 
capacidade de raciocinar, de definir e redefinir problemas, de dialogar de forma produtiva" (CARRAHER, 1988, p. 30).

Num primeiro momento, enfrentamos dificuldades com a historiografia de Canoas. A história local, até meados de 1990, encontrava-se circunscrita aos historiadores diletantes e memorialistas. Não a menosprezamos, entretanto, tem uma tendência a relatar, cronologicamente, os fatos administrativos e a explicitar, prioritariamente, a vida e a obra de grandes nomes locais. Esta historiografia, também, elege determinados acontecimentos como se estes fossem da mais alta relevância para toda a comunidade, desconectados de uma contextualização histórica mais ampla.

No trabalho realizado pelos alunos, optou-se pela utilização da História Oral como metodologia, a fim de gerar fontes históricas além das já existentes, ou seja, a documentação escrita representada por Livros Históricos de instituições locais com registros manuscritos diários, cobrindo um período de aproximadamente cem anos; jornais; documentação cartorial; diários e cartas; e fontes iconográficas como obras de arte e fotografias. 0 testemunho oral representou o núcleo da investigação, o que obrigou os graduandos a levarem em conta as relações entre escrita e oralidade, memória e história ou tradição oral e história.

Além disso, o uso sistemático do testemunho oral possibilitou 0 esclarecimento de trajetórias individuais, eventos ou processos que às vezes não têm como ser entendidos ou elucidados de outra forma, como os depoimentos desses imigrantes anônimos, moradores de determinados bairros de Canoas, com suas lutas cotidianas encobertas ou esquecidas e suas versões menosprezadas pela historiografia oficial da cidade.

0 contato mais aproximado com a população causou grande repercussão, fazendo com que ela mesma quisesse saber mais sobre a sua própria história. Segundo Bourdieu, a entrevista é um ato de comunicação 0 qual deve ser realizado, reduzindo-se ao máximo a violência simbólica presente em qualquer ato comunicacional. 0 entrevistador precisa instaurar uma escuta ativa e metódica (BOURDIEU,1997, p. 695-696). Desta maneira, garante-se que o projeto de reconstrução da memória histórica não seja uma imposição de um grupo de pesquisadores de fora, mas sim uma demanda da própria comunidade. 
A seguir, descrevemos certos procedimentos e princípios, na elaboração e no desenvolvimento do projeto:

a) Os alunos definiram a população a ser estudada

MEIHY (1998, p. 53-54) denomina como colônia o grupo composto por pessoas ligadas por características comuns, definidas a partir de critérios como condição social, sexo, idade, etnia ou outros, dependendo dos objetivos do projeto. No nosso caso, em particular, os critérios adotados foram etnia, idade e sexo.

A colônia foi formada a partir de indicação de pessoas-fonte, isto é aquelas que possuíam um conhecimento abrangente sobre os grupos de imigrantes. A busca das pessoas-fonte deu-se nas instituições dos bairros, como centros de cultura, clubes de mães (ligados à escolas), igrejas e outras. As entrevistas realizadas com estes informantes foram chamadas de ponto zero. A partir daí foram constituídas as colônias e procedeu-se a escolha dos indivíduos que seriam entrevistados.

b) Momento preparatório para a entrevista

os alunos fizeram reuniões com os indivíduos que seriam entrevistados, esclarecendo sobre os objetivos do projeto e a dimensão da sua participação. Explicitaram que precisariam usar gravadores para registrar os depoimentos, como estes seriam utilizados, depois de trabalhados, e a sua transformação em documento escrito. Estes primeiros contatos tiveram como objetivo estabelecer um relacionamento de confiança entre 0 entrevistador e o colaborador.

c) Elaboração do roteiro da entrevista

0 ato de entrevistar envolve muito mais do que seguir corretamente um roteiro e procedimentos técnicos. É preciso, fundamentalmente, que 0 entrevistador adote uma postura dialógica que envolverá manifestações verbais e não-verbais. Entrevistar é um ato de comunicação. Nem sempre os universos sócio-culturais entre entrevistador e entrevistado são compartilhados. Assim, além da instrumentalização teórico-metodológica, o entrevistador deverá ter postura ética específica para lidar com a alteridade, o que pressupõe percepção e respeito pela diferença.

PORTELLI (1997, p. 17-25) chama a atenção para que o entrevistador não se coloque frente aos entrevistados, entendendo-os apenas como 
fontes. Deve-se ter presente que são pessoas cujos depoimentos auxiliaram para a construção de conhecimentos a respeito do seu objeto de estudo. Os alunos optaram por adotar, nas entrevistas, o formato de bistória de vida. Os depoentes narraram, livremente sobre suas vidas e suas experiências pessoais. Foram formuladas questões amplas e 0 próprio entrevistado organizou cronologicamente a narrativa.

d) Tratamento dos depoimentos

Após o término da entrevista, esta foi transcrita, transpondo-se o texto oral para o escrito. Para tanto, apoiamo-nos no que THOMPSON (1998, p.293) entende por transcrição integral. Para este autor, a transcrição deve incluir tudo o que está gravado, com a possível exceção de digressões para verificar se 0 gravador está funcionando.

Após a transcrição da entrevista, foi feita a conferência, etapa na qual o depoente é convidado a conferir o documento e a interferir na forma final da sua narrativa, solicitando-se ao depoente a cessão dos direitos da entrevista para 0 entrevistador.

Durante o desenvolvimento do projeto, os entrevistadores mantiveram um caderno de campo, onde foram anotadas todas as etapas, desde os primeiros contatos, até as entrevistas.

e) A devolução do produto da pesquisa à comunidade de origem 0 produto foi um Livro-Memória, cujos exemplares foram doados para as escolas nas quais os futuros professores estavam estagiando para ser utilizado no ensino fundamental, como recurso material no ensino da história local. As fitas com as entrevistas e as transcrições foram doadas, também, para as bibliotecas das escolas.

Foi possivel perceber, primeiramente, nos depoimentos levantados pelos alunos com imigrantes idosos, o quanto a história/memória destes estava oculta e fragmentada. Em segundo lugar, este estudo da história, a partir da memória dos mais velhos, provocou enorme interesse nos futuros professores.

Muitos dos testemunhos coletados eram de pessoas que haviam imigrado para o Brasil, durante o período compreendido entre a Primeira e a Segunda Guerra Mundial (italianos, alemães, poloneses e ucranianos) e que haviam se estabelecido em Canoas, seguindo uma trajetória de perseguições, fugas, perda de familiares e desenraizamento. BOSI (1998) destaca que os espaços e a 
paisagem são fundamentais para o seguimento das tradições e da memória coletiva, sendo o desenraizamento, um fator desagregador da memória, provocando a espoliação da lembrança.

Os alunos compreenderam os desafios que subjazem à interpelação da memória quando buscaram sistematizar dados sobre a trajetória histórica dos depoentes, ou seja, os seus enfrentamentos com um novo espaço, paisagem e outros grupos sociais, a superação do estranhamento de sua nova condição e a reconstrução identitária.

Também perceberam, através dos depoimentos, que identidade é uma construção social e simbólica, a partir de um contexto e através da percepção da existência de um outro.

As entrevistas com imigrantes alemães e italianos revelaram que, durante a Segunda Guerra Mundial, estes reduziram as suas identidades ao silêncio, fizeram-nas invisíveis, frente ao contexto em que viviam. Relatos recolhidos nos Livros Históricos do Instituto São José - instituição escolar canoense que deu origem ao Centro Universitário La Salle -, narram as perseguições que moradores da cidade faziam aos alemães que ali residiam. Após o conflito, passadas algumas décadas, as identidades emergiram, sendo remanejadas, de acordo com as novas situações concretas, vivenciadas por indivíduos e grupos.

Isto levou os alunos a concluírem sobre as diferentes configurações de identidade e como estas foram construídas e reconstruídas nos diversos momentos da história dos indivíduos e grupos pesquisados. Também, refletiram sobre os sistemas de relações que ligam as pessoas, ou seja, as sociabilidades, os compromissos, as reciprocidades e as interações.

A iniciação dos alunos de Licenciatura na abordagem da história local, utilizando depoimentos orais como fontes, levou-os a lidar com a pesquisa histórica sistemática, especialmente com as diferentes versões históricas; com questionamento e discussão sobre identidades, alianças, diferenças; com a noção de cultura como produto histórico, dinâmico e flexível, segundo SAHLINS, alterada historicamente na ação (1990, p.9); bem como de interação entre o passado, a história, a memória e a realidade atual.

0 domínio técnico contribuiu para ampliar os suportes da memória e torná-los mais acessíveis aos alunos, principalmente no desenvolvimento da preocupação de se ensinar e pesquisar a história local. 


\subsection{Ensino de História através de projetos: 0 uso das fontes orais no ensino fundamental}

Um projeto de trabalho representa uma situação de ensino através da qual o professor e os alunos refletem, discutem e organizam atividades voltadas para a realização de um produto final sobre um determinado tema. É uma seqüência de ações compartilhadas que promovem oportunidades para que os alunos desenvolvam competências e habilidades como: justificativa de escolhas com base em juízos de valor; construção da identidade pessoal e social na dimensão histórica; capacidade argumentativa; capacidade lecto-escrita; socialização de informações, entre outras.

Este tipo de atividade de ensino e de aprendizagem promove, também, a possibilidade de os alunos assumirem compromissos, de definirem papéis e construírem uma maior consciência e responsabilidade de sua auuação nas aulas, pois ao montarem o projeto de trabalho passam por um processo que thes desvela o por quê e para quê estudam um determinado tema.

No ensino da História, os projetos permitem trabalhar com temáticas variadas, extrapolando os conteúdos que estão postos, formalmente, nos Planos de Estudos dos Ensino Fundamental e Médio. Além disto, os projetos permitem trabalhar, integradamente, de forma inter ou multidisciplinar com outras áreas do conhecimento, sobretudo com a Geografia, a Língua Portuguesa e a Educação Artística. Isso proporciona aos alunos a oportunidade de estabelecer relações entre fatos, conceitos e procedimentos das diferentes áreas para 0 entendimento de um fenômeno social ou cultural, vindo a construir compreensões mais amplas sobre um mesmo tema, percebendo-0 a partir de diferentes pontos de vista.

0 projeto de trabalho com história oral deve iniciar por situaçõesproblema que deverão ser levantadas pelos alunos, auxiliados pelo professor, a partir da socialização de experiências, de reflexões e de debates, bem como informações iniciais. A seguir, formulam-se, em conjunto, os problemas que desafiem os alunos a buscar informações, trocar idéias, discutir e tomar decisões, agrupando-se aqueles em torno de um tema.

Procede-se à identificação da relevância social, intelectual, cultural ou política do projeto e a elaboração dos objetivos. Determina-se, então, com os 
alunos, as etapas que serão percorridas para que os problemas sejam solucionados, definindo fontes a serem consultadas, tarefas e prazos , combinando a função de cada aluno ou grupo de alunos (bem como a do professor). Decide-se, por fim, qual será o produto final do projeto de trabalho e como este será socializado com a escola e comunidade e como será a avaliação dos resultados.

0 ensino de História por projetos de trabalho tem de contar com flexibilidade de tempo, uma vez que sua duração corresponde ao tempo necessário para se alcançar os objetivos. Além disso, é necessário que os alunos sej̣am iniciados, antes da formulação do projeto com a utilização da história oral: em atividades de instrumentalização (o que é história oral, a realização das entrevistas, a sua transcrição e validação), planejamento e divisão de responsabilidades; e a trabalhar em grupos.

Sequiência de projeto de trabaho com história oral

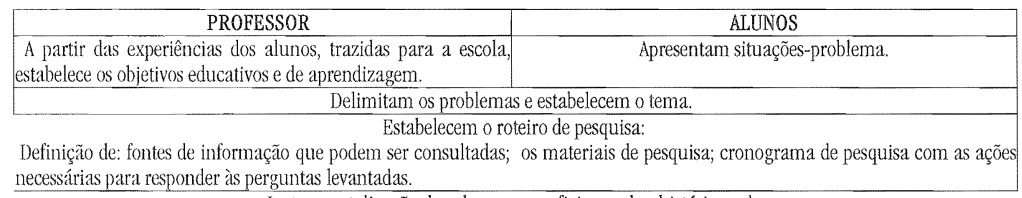

Instrumentalização dos alunos com oficinas sobre história oral.

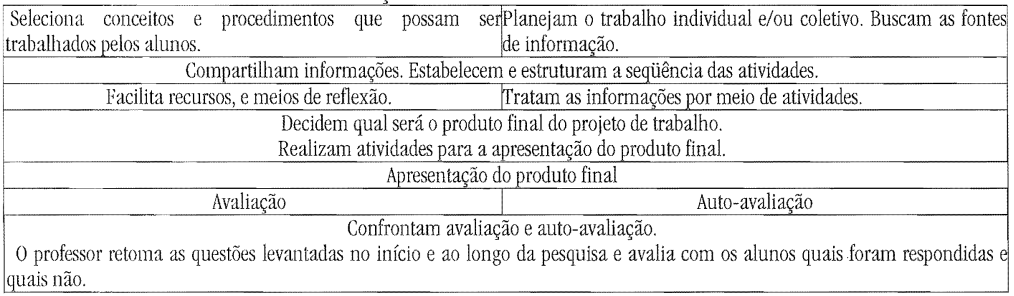

Fonte: HERNÁNDEZ e VENTURA, 1998.

A partir dos pressupostos citados, os alunos da Disciplina de Prática de Ensino I, do curso de História desenvolveram uma experiência de ensino em seus estágios no Ensino Fundamental. o Projeto denominou-se:Vestígios, Memória e História de Bairros.

A atividade visava aos alunos de quinta série do Ensino Fundamental e inseriu-se nos conteúdos trabalhados pelo professor na unidade Urbanização 
do Brasil. 0 recorte espacial foi o das cidades de Canoas e Sapucaia, o que se justifica, tendo em vista a procedência dos graduandos do curso de História do Centro Universitário La Salle, Canoas.

0 estudo do espaço urbano permitiu a aproximação com as experiências cotidianas vivenciadas por homens e mulheres, e destacar os tipos de relações desenvolvidas entre os diferentes atores históricos.

0 recorte cronológico teve como marcos a década de quarenta, período em que as cidades de Canoas e Sapucaia se emanciparam e 0 ano de 1980, a partir do qual se instauraram mudanças significativas nas mesmas.

0 Projeto teve por objetivo, proporcionar, tanto aos futuros professores quanto aos alunos com os quais estavam estagiando, 0 acesso à manifestações orais e materiais da memória de moradores dos bairros e as suas relações com o processo histórico das cidades de Canoas e Sapucaia. Buscou, também, familiarizá-los com as formas pelas quais a memória presentifica o passado oralmente, e como constrói e reconstrói representações do vivido, traduzido por atitudes, costumes, hábitos, atividades, formas de relacionar-se com vizinhos, parentes, autoridades, entre outros. Isso abriu, tanto para os futuros docentes quanto para os alunos com os quais trabalhavam, a visualização da multiplicidade de elementos que compõem o cotidiano das pessoas no passado e no presente.

0 Projeto revelou, através das narrativas, a perspectiva do moradores dos bairros sobre as estruturas sociais, políticas, culturais e econômicas de sua comunidade e sociedade. A comparação dessas com as narrações e explicações oferecidas por outras fontes como jornais, documentos primários e pelas obras dos memorialistas das cidades de Canoas e Sapucaia, mostraram como eventos relatados (vividos ou não) pelas pessoas, puderam ter outras versões e interpretações. Segundo COSTA, o "exame de fontes" exercita a "...crítica da escrita da história, ou seja, a historiografia. Esse é o modo de viver a interpretação, de aprender a fazer sínteses teóricas, de prosseguir em busca de novos conhecimentos..." (2003, p. 204).

Os alunos perceberam como as pessoas envolvidas direta ou indiretamente, ou aqueles que apenas testemunharam certos eventos, raramente, possuíam uma visão exata de todas as circunstâncias e detalhes que construíram e explicaram os eventos. Ficou explícito que a história deve procurar ir além da 
simples aparência, deve descobrir as forças que agem na sociedade, seus potenciais de influência, os objetivos a que visam alcançar e os motivos que as movem, que vão além de discursos e muitas vezes em direção oposta a estes.

0 trabalho envolveu a preparação do projeto, busca das pessoas-fonte dos mais diversos segmentos sociais da comunidade, preparação das entrevistas, coleta de depoimentos, transcrição das entrevistas, análise dos testemunhos. Permitiu a utilização de recursos tecnológicos como a máquina fotográfica, câmera de vídeo, o computador e o gravador.

0 produto final gerado foi uma exposição constituída de painéis elaborados a partir de fotografias e depoimentos orais, patrocinada por estabelecimentos comerciais e industriais dos bairros.

\section{Conclusão}

O estudo que utilize fontes orais e sua posterior guarda em uma instituição de memória (museu, arquivo histórico, biblioteca) oferece-se às comunidades como meio de comunicação e educação, para que cada grupo, apropriandose dele, produza sua própria expressão e the dê utilidade, assegurando que a memória materializada em fitas e transcrições possa ser exposta, de forma sistematizada e que seja transformada em patrimônio cultural.

0 argumento favorável à inserção de fontes orais no ensino de história, passa pela aceitação de que é fundamental compreender que existem modos de proceder baseados em duas maneiras diferentes de tratar o documento: um que confere maior importância à precisão factual e à informação e outro mais preocupado com o que revelam as interpretações sobre os fatos.

No segundo caso, trata-se, basicamente, da narrativa do indivíduo, de suas experiências e é limitada pelo tempo possível de vida que se testemunhou. São os denominados testemunhos voluntários, não restritos às fontes orais, integrados também por autobiografias, diários etc., produzidos com a intencionalidade de narrar uma experiência para o conhecimento dos demais.

0 trabalho com fontes alternativas, como as orais, pode fazer com que 0 ensino de história caminhe em direção a muitas descobertas. Os depoimentos estão repletos de práticas de resistência, vivências cotidianas e processos societários. Num mundo que perde as suas referências, o trabalho com a memória, valorizando a experiência social, oferece a aproximação com os 
sujeitos históricos com todo o impacto das representações que estes fazem de si e do mundo, bem como auxilia a manter uma atitude consciente na tarefa de reinventar a vida e no modo de pensar a história.

Como agentes de sua própria história, os depoentes são sujeitos sociais que, de forma autônoma, agem, pensam, criam e transformam seu próprio mundo, partilham vivências, produzem conflitos, definem e redefinem significados de crenças, valores, atitudes e hábitos. Isto pode ser desvelado através de suas memórias.

A Universidade e a escola são espaços de reflexão e criação, logo, 0 trabalho com fontes orais proporciona condições de levar ao estudo e a divulgação de um passado passível de várias leituras críticas, auxiliando na construção de uma postura menos dogmática e mais acolhedora às diferenças inerentes aos processos de vida.

\section{Referências}

ALBERTI, V. Historia oral: a experiência do CPDOC. Rio de Janeiro: FGV, 1990.

BOSI, Ecléa. Memória e sociedade - lembranças de velhos. 6 ed. São Paulo: Schwarcz LTDA, 1998.

CAMARGO, A. Como a História Oral chegou ao Brasil. Simpósio Nacional da Associação Nacional de História (20:1999: Florianópolis), História: fronteira. Associação Nacional de História, v. II. São Paulo: Humanitas/FFLCH/USP/ANPUH, 1999.

CARRAHER, D. W. A grande função da escola: ensinar a pensar. In: Sala de aula, ano $1, \mathrm{n}^{0} 3$, junho 88 .

COSTA, Suely Gomes. Gênero e História. In: ABREU, Marta; SOIHET', Rachel. Ensino de bistória: conceitos, temáticas e metodologia. Rio de Janeiro: Casa da Palavra, 2003.

CRUIKSHANK, J., "Tradição oral e história oral: revendo algumas questões". In: AMADO, J., FERREIRA, M. de M. (Coord.) Usos e abusos da História Oral, Rio de Janeiro, Editora da Fundação Getúlio Vargas, 1996.

DEBERT, Guita. Problemas relativos à utilização da história de vida e história oral. In: CARDOSO, Ruth (org.) Aventura antropológica, teoria e pesquisa. Rio de Janeiro: Paz e Terra, 1986.

FERREIRA, M. de M. (org). História Oral e Multidisciplinaridade. Rio de Janeiro: Diadorim, Rio de Janeiro, 1994. 
FERREIRA, M. \& AMADO, J. (org.). Usos e abusos da bistória oral. Rio de Janeiro: FGV, 1996.

HERNÁNDEZ, Fernando e VENTURA, Monstserrat. A organização do curriculo por projetos de trabalbo. 0 conhecimento é um caleidescópio. 5. ed. S.P. Artmed, 1998.

LOPES, Marcos Antônio (org.). COSTA, Suely Gomes. Gênero e História. In: ABREU, Marta; SOIHET, Rachel. Ensino de bistória: conceitos, temáticas e metodologia. Rio de Janeiro: Casa da Palavra/. São Paulo: Contexto, 2003.

MANIQUE, A. P.; PROENÇA, M. C. Didáctica da bistória - Patrimônio e bistória local. Lisboa: Texto Editora, 1994.

MEIHY, José Carlos Sebe Bom. Manual de história oral. 2. ed. São Paulo: Loyola, 1998.

NORA, Pierre. Entre memória e história A problemática dos lugares. In: Projeto História, São Paulo: CEDUC, n. 10, dezembro/1993, p. 7-46.

PARÂMETROS Curriculares Nacionais. Ministério da Educação e do Desporto/Secretaria de Educação Fundamental, Brasília, 1998.

PENNA, Rejane. A utilização das fontes orais na bistoriografia do Rio Grande do Sul: novas perspectivas ou falsos avanços? Tese apresentada para a obtenção de grau de Doutor junto ao Programa de Pós-Graduação em História da Pontifícia Universidade Católica do Rio Grande do Sul, Porto Alegre, 2003.

PORTELLI, Alessandro. Tentando aprender um pouquinho. Algumas reflexões sobre a ética na história oral. In: Projeto História, n 15, Abril/97, p. 13-50.

REVEL, Jacques. Microanálise e construção do social. In: REVEL, Jacques. Jogos de escalas. A experiência da microanálise. Rio de Janeiro: Editora da Fundação Getúlio Vargas, 1988, p.15 a 38.

SAHLINS, Marshall. Cosmologias do capitalismo: o setor transpacífico do "Sistema Mundial". Anais da XV Reunião Brasileira de Aniropologia [snt] p. 47-106.

SAHLINS, Marshall. Ilhas de bistoria. Rio de Janeiro: Zahar, 1990.

SAMUEL Raphael. História local e história oral. Revista Brasileira de História, vol. 9 , no 19. São Paulo: Anpuh/Marco Zero, st., p. 219-243, 1989.

SILVA, Helenice Rodrigues. Entre memória e História em Paul Ricoeur. In: LOPES, Marcos Antônio. Grandes nomes da bistória intelectual. São Paulo: Contexto, 2002.

THOMPSON, Paul. A Voz do Passado: bistória oral. 2. ed. São Paulo: Paz e Terra, 1998.

VIEIRA, M. P. A. et alli - A pesquisa em bistória São Paulo: Ática, 1991. 


\section{Telling life, thinking about history, experiences on the oral sourse in history teaching}

\section{Abstract}

This article has as main objective to make us think about the oral depositions as source to the study of history and the recourses for its teaching. It presents experience with the classroom work, which led us to conclude that the work with memory - valuing the social experience - provides elements to reflection about the representations that the hisiorical subjects make of themselves and also about the world. It also helps to maintain a concious attitude in the task of reinvent life and of thinking about history.

Key words: history, memory, oral source, teaching. 